\title{
Início de um novo ano e muitas novidades para os $A B D$
}

\author{
The beginning of a new year brings exciting changes for the $A B D$
}

We start the year with very good news: according to the statute of the Brazilian Society of Dermatology (SBD), we now have an additional Associate Editor, Mr. Ayres Andrela Fralete Vallarelli, from Campinas-SP, who holds an M.Sc. and a Ph.D. in Dermatology from UNICAMP. We believe that his knowledge and enthusiasm will add much value to the ABD.

In the first issue of 2011, in the section "Images in Dermatology", we bring the article titled "Dermoscopy features for the diagnosis of furuncular myiasis", which is further illustrated with a video uploaded to our website. This is an extra resource made available by the ABD to the authors who submit their work to the journal and would like to enhance their articles by making use of such materials.

We would like to remind you that original articles may be submitted in English or Portuguese until April of 2011. From this date on, they must be submitted in English only for the reasons stated in the last editorial and now quickly summarized: greater possibility of global exchange of scientific information among the authors (which is why we eagerly fought for so many years for indexation in Medline), bigger pool of reviewers, less chance of inadequate translations done by non-authors and, lastly and inevitably, greater international visibility of our journal and of the Brazilian dermatology. To make this process easier and more efficient, we will count on reviewers who are experienced dermatologists members of the SBD - and also fluent in English. They will be of crucial importance in this major shift.

For practical purposes, the sections: "What is your diagnosis?" and "Syndrome in question" will merge and have a new print format to facilitate the process of diagnosis by the reader.

Another change in our bimonthly issue is the paper used in the print version of the journal, which is now couché mate, a more economical and environmentally appropriate type of paper. It is woodand acid-free, which are recommendations of the National Library of Medicine, associated with MEDLINE. Moreover, these new features do not alter the good quality of the product.

Also, the website, which brings the online version of the journal, has been revised and we hope that the advanced search of active items becomes more efficient for the readers. Later this year, to facilitate the electronic reading of the articles, we also intend to introduce the format for $e$-books.

Once again, we wish all our colleagues - readers and authors - and our editorial team, a wonderful 2011. 